\title{
Ginkgo biloba Extract (GbE): Promising Therapeutic Perspective to Treat Obesity and Diabetes
}

\author{
Bruna Kelly Sousa Hirata, Jéssica de Souza Figueiredo and Monica Marques Telles* \\ Department of Biological Sciences, Universidade Federal de São Paulo, Brazil
}

Submission: July 29, 2017; Published: July 31, 2017

*Corresponding author: Monica Marques Telles, Department of Biological Sciences, Universidade Federal de São Paulo, Brazil, Tel: +55 1140440500, Email: mmtelles75@gmail.com

\begin{abstract}
Since obesity and its co-morbidities have become huge public health problems, it is uncountable the requirement of new approaches to treat both obesity and its related disorders. Conventional pharmacological anti-obesogenic therapies present several unwanted effects which represent serious health risk. Therefore, new therapeutic alternatives are necessary to control body weight gain in order to reduce the associated diseases development, such as type 2 diabetes (T2D). Ginkgo biloba Extract (GbE) has been recently described as a potential anti-obesogenic and hypoglycemic agent since it reduced food/energy intake, body weight gain and visceral adiposity as well as improved insulin signaling and sensitivity in obese rats. Considering the beneficial effects observed in an experimental model of obesity, GbE has been pointed as a new therapeutic perspective for both obesity and T2D treatment.
\end{abstract}

Keywords: Ginkgo biloba Extract; Obesity; Diabetes; Insulin resistance; Body weight control; Herbal medicines

Abbreviations: GbE: Ginkgo Biloba Extract; T2D: Type 2 Diabetes; STZ: Streptozotocin; PTP-1B - Protein Tyrosine Phosphates 1B; IR: Insulin Receptor; IRS-1: Insulin Receptor Substrate 1; Akt: Protein Kinase B; AdipoR1: Adiponectin Receptor Protein 1; TNF-alpha: Tumor Necrosis Factor Alpha; NFkappaB-p65-Nuclear Factor Kappa B-p65

\section{Introduction}

Obesity has become a major public health problem worldwide. In 2014, approximately 1.9 billion (39\%) of adults were overweight, while 600 million (13\%) were obese; in some countries, overweight and obesity prevalence has already achieved more than $70 \%$ of the population [1]. Many comorbidities are associated with obesity such as cardiovascular diseases, musculoskeletal disorders, cancer and diabetes, which is also considered as a global public health problem [1,2] and for this reason, fighting obesity has constituted a huge challenge in the last decades. Non-pharmacological approaches are undoubtedly of great value, but tend to have limited long-term results [3]. Although several anti-obesogenic drugs are released for medical purposes, there are only few medications currently available to treat obesity [3-5]. According to the U.S. Department of Health and Human Services, five drugs - orlistat, lorcaserin, naltrexonebupropion, liraglutide and phentermine-topiramate - are approved to long-term treatment of obesity without important side effects [4]. Even being effective, some anti-obesogenic pharmacological therapies have been historically linked to serious side effects, such as pulmonary hypertension, cardiovascular events and psychiatric disorders [5]. However, neglecting obesity treatment might also result in serious health risks and the development of new and safe therapeutic alternatives is highly necessary.

Diabetes is one of the most worrisome obesity-related complications. In the last three decades, the number of diabetic patients tripled across the globe, rising from 108 million adults in 1980 to 422 million in 2014, and it has been estimated that about 642 million people will develop diabetes until 2040 [6,7]. Diabetes is associated to multiple complications such as blindness, amputation, stroke, kidney failure, neuropathies, among others [7], reducing the quality of life and life expectancy. Since the type 2 diabetes (T2D) is a multifactorial disorder, several glucose lowering agents with different targets are currently available [4]. Regarding their chemical properties and mechanisms of action, these drugs are usually classified as insulin sensitizers, insulin releasing drugs (or secretagogues), alpha glucosidase inhibitors, incretin-based medications and insulin therapy $[4,5,8,9]$. In spite of being effective in most cases, the pharmacological therapy of T2D has some undesirable side effects, including hypoglycemia, weight gain or loss, gastrointestinal disorders, angioedema and cardiovascular events, among others $[4,8,10,11]$. The unwanted effects of hypoglycemic drugs have encouraged searching for new 


\section{Current Research in Diabetes \& Obesity Journal}

approaches to treat $\mathrm{T} 2 \mathrm{D}$ and its related disorders, especially the ones based on natural products.

\section{Discussion}

Herbal medicines have been used for centuries in the treatment of several diseases. Ginkgo biloba extract (GbE) is one of the most widely used herbal medicines in the world and classically has been used to treat neurodegenerative diseases such as Alzheimer [12], memory loss, schizophrenia, mild cognitive impairment, dementia [13] as well as cancer and cardiovascular sicknesses [14]. Beneficial effects of GbE on both obesity and T2D have recently been described $[15,16]$ highlighting $\mathrm{GbE}$ as a new therapeutic perspective for obesity and T2D.

Due its antioxidant, anti-inflammatory and ant apoptotic properties, GbE has been explored as a hypoglycemic and insulin sensitizing agent [17]. It also has been associated with the prevention of retinal ganglion cells damage [18], protection against pancreas inflammation in STZ-induced diabetic mice [19], cardioprotection in STZ-induced diabetic rats [20], improvement on glucose homeostasis and successful protection against atherosclerosis in a rat model of T2D [21]. Additionally, in humans GbE reduced glycosylated hemoglobin A levels in T2D patients [17]. GbE was recently described as a promising anti-obesogenic agent since it has been demonstrated an inhibitory effect of this extract on food/energy intake, body weight gain and visceral adiposity of diet-induced obese rats. Additionally, GbE significantly improved insulin sensitivity and stimulated the insulin pathway cascade through enhancing insulin receptor substrate 1 (IRS-1) while it reduced PTP-1B (a negative regulator of insulin signaling pathway) levels in the gastrocnemius muscle. Furthermore, GbE promoted higher AKT phosphorylation in both in retroperitoneal white adipose tissue depot and retroperitoneal adipose tissue depot as well as it increased Phosphorylated IR expression in the retroperitoneal white adipose tissue depot $[15,16]$. It was also demonstrated a significant increase on the adiponectin receptor (AdipoR1) gene expression with a concomitant reduction on TNF-alpha levels and NFkappaB-p65 phosphorylation in gastrocnemius muscle [16]. These findings allowed the authors to suggest that GbE has a potential to improve both energy and glucose homeostasis and it might be especially valuable to obese subjects who are resistant in adopting a healthy lifestyle.

\section{Conclusion}

Due to the unwanted side effects of the anti-obesogenic and anti-diabetic drugs, the development of an effective and safe therapy remains a challenge. GbE, one of the most widely used herbal medicines in the world, has been pointed as a new therapeutic perspective for obesity and T2D. GbE presents antioxidant, anti-inflammatory and anti-apoptotic properties and recent studies in obese rats have described that this herbal medicine might be useful to reduce both body weight and adiposity as well as to improve glucose intolerance. However, clinical studies must be performed in order to elucidate if the beneficial effects of
GbE observed in an experimental model of diet-induced obesity may represent a real pharmacological alternative to treat both obesity and T2D in humans.

\section{References}

1. World Health Organization (2016) Obesity and Overweight.

2. World Health Organization (2016) Obesity and Diabetes: the slowmotion disaster. 47 th meeting of the National Academy of Medicine, USA.

3. Qaseem A, Humphrey LL, Sweet DE, Starkey M, Shekelle P, et al. (2016) Oral pharmacologic treatment of type 2 diabetes mellitus: a clinical practice guideline update from the American College of Physicians. Ann Intern Med 156(3): 218-231.

4. Rodgers RJ, Tschöp MH, Wilding JPH (2012) Anti-obesity drugs: past, present and future. Dis Model Mech 5(5): 621-626.

5. Hendricks J (2017) Off-label drugs for weight management. Diabetes Metab Syndr Obes 10: 223-234.

6. World Health Organization (2016) Global Report on Diabetes. WHO Library, Switzerland, pp. 1-87.

7. International Diabetes Federation (2015) IDF Diabetes Atlas. ( $7^{\text {th }}$ edn), International Diabetes Federation, Belgium, pp. 1-142.

8. Mancini MC, Melo ME (2017) The burden of obesity in the current world and the new treatments available: focus on liraglutide $3.0 \mathrm{mg}$ Diabetol Metab Syndr 9: 44.

9. (2016) U.S. Department of Health and Human Services. Prescription medications approved for overweight and obesity treatment.

10. Trasher J (2016) Pharmacologic management of type 2 diabetes mellitus: available therapies. Am J Cardiol 130(1S): S4-S17.

11. Dardano A, Penno G, Del Prato S, Miccoli R (2014) Optimal therapy of type 2 diabetes: a controversial challenge. Aging (Albany NY) 6(3): 187-206.

12. Ramassamy C, Longpré F, Christen Y (2007) Ginkgo Biloba Extract (EGb 761) in Alzheimer's Disease: Is there Any Evidence? Curr Alzheimer Res 4(3): 253-262.

13. Zhang H, Huang L, Zhong Yan Biao, Zhou Qi Hui, Wang Hui Lin, et al. (2016) An Overview of Systematic Reviews of Ginkgo biloba Extracts for Mild Cognitive Impairment and Dementia, Front Aging Neurosci 8: 276.

14. Mahadevan S, Park Y (2008) Multifaceted therapeutic benefits of Ginkgo biloba L: chemistry, efficacy, safety, and uses. J Food Sci 73(1): R14-R19.

15. Banin RM, Hirata BK, Andrade IS, Zemdegs JC, Clemente AP, et al (2014) Beneficial effects of Ginkgo biloba extract on insulin signaling cascade, dyslipidemia, and body adiposity of diet-induced obese rats. Braz J Med Biol Res 47(9): 780-788.

16. Hirata BK, Banin RM, Dornellas AP, de Andrade IS, Zemdegs JC, et al (2015) Ginkgo biloba extract improves insulin signaling and attenuates inflammation in retroperitoneal adipose tissue depot of obese rats. Mediators Inflamm 2015: 419106.

17. Kudolo GB, Wang W, Javors M, Blodgett J (2006) The effect of the ingestion of Ginkgo biloba extract (EGb 761) on the pharmacokinetics of metformin in non-diabetic and type 2 diabetic subjects--a double blind placebo-controlled, crossover study. Clin Nutr 25(4): 606-616.

18. Huynh T, Mann S, Mandal Nawajes (2013) Botanical Compounds: Effects on Major Eye Diseases. Evid Based Complement Alternat Med 2013: 549174. 


\section{Current Research in Diabetes \& Obesity Journal}

19. Rhee K, Lee C, Kim S, Gim D, Kim H, et al. (2015) Extract of Ginkgo Biloba Ameliorates Streptozotocin-Induced Type 1 Diabetes Mellitus and High-Fat Diet-Induced Type 2 Diabetes Mellitus in Mice. Int J Med Sci 12(12): 987-994.

20. Saini AS, Taliyan R, Sharma PL (2014) Protective effect and mechanism of Ginkgo biloba extract-EGb 761 on STZ-induced diabetic cardiomyopathy in rats. Pharmacogn Mag 10(38): 172-178.
21. Lim S, Yoon JW, Kang SM, Choi SH, Cho BJ, et al. (2011) EGb761, a Ginkgo biloba extract, is effective against atherosclerosis in vitro, and in a rat model of type 2 diabetes. PLoSOne 6(6): e20301.
Your next submission with Juniper Publishers will reach you the below assets

- Quality Editorial service

- Swift Peer Review

- Reprints availability

- E-prints Service

- Manuscript Podcast for convenient understanding

- Global attainment for your research

- Manuscript accessibility in different formats (Pdf, E-pub, Full Text, Audio)

- Unceasing customer service

Track the below URL for one-step submission https://juniperpublishers.com/online-submission.php 